\title{
La unidad en la diversidad de la humanidad en José Martí
}

\author{
Marcelino R. Rojas ${ }^{1}$
}

Recibido en agosto de 2014, aceptado en noviembre de 2014

\begin{abstract}
"No hay odio de razas, porque no hay razas. Los pensadores canijos, los pensadores de lámparas, enhebran y recalientan las razas de librería, que el viajero justo y el observador cordial buscan en vano en la justicia de la Naturaleza, donde resalta en el amor victorioso y el apetito turbulento, la identidad universal del hombre". ${ }^{2}$
\end{abstract}

José Martí.

\begin{abstract}
Resumen
El presente artículo trata sobre la visión de José Martí sobre la realidad humana, su unidad en la diversidad y su diversidad en la unidad. Para Martí la humanidad, aunque diversa en sus culturas, en sus caracteres étnicos, en su educación y en sus labores es una. Y cualquier humano, o sea todos, es digno de respeto y buen trato, y ha de participar de los bienes que la naturaleza y la humanidad proporcionan.
\end{abstract}

Palabras claves

Unidad, diversidad, humanidad, humano, razas.

\begin{abstract}
This article presents José Martí's work on human reality, its unity within diversity, and its diversity within unity. According to Martí, although diverse in its cultures, ethnical traits, education, and labor types, humanity is one. Any human being, which means everybody, deserves to be respected, well-treated, and benefitted by the goods that nature and humanity offer.
\end{abstract}

\section{Keywords}

Unity, diversity, humanity, human, race.

Según José Martí, "No hay razas: no hay más que modificaciones diversas del hombre, en los detalles de hábito y formas que no les cambian lo idéntico y esencial, según las condiciones de clima e historia en que viva." ${ }^{3} Y$, aunque, pareciera claro y contundente, este escrito presentará, desde el mismo José

\footnotetext{
1. Marcelino Rojas: Profesor de Antropología Filosófica, Universidad Don Bosco, El Salvador. Email: rojas.marcelino@gmail.com

2. Martí, José. Nuestra América. Obras Completas. Edit. Nac. de Cuba. La Habana, 1965.

3. Martí, José. La verdad sobre los Estados Unidos, Patria, Nueva York, 23 de marzo de 1894, t.28, p.290.
} 
Martí y de los especialistas de su pensamiento, su idea acerca de la unidad en la diversidad de la humanidad.

Para Martí, “El hombre no tiene ningún derecho especial porque pertenezca a una raza u otra: dígase hombre, y ya se dicen todos los derechos"4. De uno a otro lugar de la tierra se van a encontrar unos y otros humanos, de distinto color, estatura, cultura, religión, sociedad o forma de gobierno. A estas diferencias se les ha nombrado raza o razas. Sin embargo, no existen tales razas. Los humanos pertenecen a la misma especie. La especie es una, aunque los humanos sean diversos. Se trata de la diversidad de la humanidad y de la unidad de la humanidad en la diversidad.

Martí experimentó esta unidad de la humanidad desde los principios de su infancia, como él mismo cuenta, recordando la ocasión en que vio azotar a un humano: "Quien ha visto azotar a un negro, ¿no se considera siempre su deudor? Yo lo vi cuando era niño, y todavía no se me ha apagado en las mejillas la vergüenza... Yo lo vi y me juré desde entonces su defensa." ${ }^{5}$ La sensibilidad de Martí desde temprana edad entrevé la humanidad existente en el negro, tanto que se promete su defensa como un juramento que lo acompañará durante toda su vida. Blancos y negros son humanos. De igual manera, para Martí los indígenas son humanos.

Aunque, en los tiempos que hoy corren no existe la esclavitud, y ya nadie la defiende como una ley jurídica o como el derecho de una especie superior sobre otra especie inferior, sigue permaneciendo una cultura de la división, que separa a unos humanos de otros por sus diferencias étnicas, culturales, políticas, económicas, religiosas, y últimamente de género.

Para otros, la diversidad es entendida como enemiga de la unidad. Lo distinto es entendido como un peligro para eliminar. Nada más contrario a la visión de Martí. Según Marinelo, las dos vías maestras en que se muestra la más inviolable condición de Martí son su culto a la unidad y a la libertad del hombre. ${ }^{6}$

Además, añade Marinelo:

El culto a la unidad y a la libertad del hombre son inseparables de su perspectiva y de su acción, y esto lo conduce a mantener, frente a todas las circunstancias, un enjuiciamiento de esencial justicia y larga vigencia. A través de toda su escritura, tan cuantiosa y varia, enarbola Martí lo que llama la identidad fundamental humana. Su ataque

4. Martí, José. Mi raza, Patria, Nueva York, 16 de abril de 1893, t.2, p.298.

5. Ibidem.

5. Marinelo, Juan. Fuentes y raíces del pensamiento de José Martí. Fundación Biblioteca de Ayacucho. Caracas. 2005.

6.Ibidem. 
al prejuicio racial no es más que una manifestación de ese concepto cardinal, concentrado en su reiterada sentencia: "hombre es más que blanco, más que mulato, más que negro". Para él todo ser humano es una entidad invulnerable, merecedora de los mismos respetos y estímulos en cualquier espacio y tiempo en que aliente. ${ }^{7}$

Es tan importante para Martí su cosmovisión de unidad y humanidad que dirá frente al afán imperialista de Estados Unidos que "La acción imperialista hiere en lo más hondo la unidad del hombre". ${ }^{8} \mathrm{Y}$, hiere, sobre todo las esperanzas de los pueblos latinoamericanos en sus anhelos de libertad porque siembra en ellos la división, que requiere el imperio para someterlos.

Martí afirmará refiriéndose a San Martín, que "ese mismo concepto salvador de América, lo llevaría a la unificación posible de sus naciones hermanas en espíritu, ocultó a sus ojos las diferencias, útiles a la libertad, de los países americanos, que hacen imposible su unidad de formas. ${ }^{9}$

Más adelante, Martí añadirá sobre San Martín:

Acaso, en su sueño de gloria, para la América y para sí, no vio que la unidad de espíritu, indispensable a la salvación y dicha de nuestros pueblos americanos, padecía, más que se ayudaba, con su unión en formas teóricas y artificiales que no se acomodaban sobre el seguro de la realidad: acaso el genio previsor que proclamó que la salvación de nuestra América está en la acción una y compacta de sus repúblicas, en cuanto a sus relaciones con el mundo y al sentido y conjunto de su porvenir. ${ }^{10}$

También Marinelo afirma que nadie como Martí definió la necesidad de derrotar al imperialismo "con la cerrada unidad de sus víctimas. De la unión -clamaba Martí- depende nuestra vida". ${ }^{11}$

Sin embargo, Martí no pregonó ingenuamente la unidad de las Repúblicas Latinoamericanas anulando su diversidad, sino afirmando su diversidad y su derecho a la libertad, como lo puso en claro al afirmar que cualquier tratado entre Repúblicas "iha de ser el tratado libre, sin compulsión y sin alcaides ejecutores, hecho de mano honrada para el bien de 'nuestros países respectivos y para la causa de la humanidad!' Y si no, no". ${ }^{12}$

\footnotetext{
8. Ibidem.

9. Martí, José. San Martin. Patria, Nueva York, 4 de noviembre de 1893.

10. Ibidem.

11. Marinelo, Juan. Op cit.

12. Martí, José. La Conferencia de Washington. El Proyecto de Arbitraje. La Argentina abre el debate. Actitud de Chile. Discurso dramático de Blaine. Quintana y Blaine. La Argentina protesta.
} 
Se ha de hacer hincapié en que la visión de Repúblicas libres hace referencia a la visión de Martí de humanos libres, y de que tales humanos, aunque pertenezcan a repúblicas diferentes, pertenecen todas ellas a una misma humanidad, como bien lo afirma el maestro, se trata del bien de los países respectivos y "para la causa de la humanidad". La humanidad es una y libre aunque existen distintas repúblicas libres e independientes. Para Martí se trata de una misión que ha cumplir cualquier humano. Y, según, el mismo Martí no "hemos de ser traidores a lo que nos mandaran hacer la naturaleza y la humanidad”. ${ }^{13}$

La visión de unidad de la humanidad en Martí es tan profunda que lo llevará a afirmar que "la Humanidad no se redime sino por determinada cantidad de sufrimiento, y cuando unos la esquivan, es preciso que otros la acumulen, para que así se salven todos". ${ }^{14}$

Martí se siente con una misión, y la quiere para todos humanos que habitan la tierra. Sin embargo, dicha misión se realiza en un mundo convulsionado por divisiones y luchas. Y será el esfuerzo sufriente de unos los que conduzcan a la humanidad a su libertad, como bien lo afirma Martí refiriéndose a Bolívar, para hacer un llamado a todos los humanos: “¡Al brazo de los hombres para que defiendan de la nueva codicia, y del terco espíritu viejo, la tierra donde será más dichosa y bella la humanidad!"15

En la lucha por la libertad de unos países respecto de otros, está en juego que la humanidad entera sea más bella y dichosa. Así se refería Martí hablando de Heredia:

"Del país profanado en que le tocó nacer, y exaltó desde la infancia su alma siempre dispuesta a la pasión, buscó amparo en la grandeza de su tiempo, reciente aún de la última renovación de la humanidad, donde, como bordas de fuego de un mar torvo, cantaba Byron y peleaban Napoleón y Bolívar". ${ }^{16}$

Sin embargo, para Martí, refiriéndose a Henríquez y Carvajal, son “escasos, como los montes, los hombres que saben mirar desde ellos, y sienten con entrañas de nación, o de humanidad." 17 De ahí la rareza con que Martí y el mismo Henríquez y Carvajal representan a esos pocos humanos que con una visión y misión de humanidad realizan una práctica muy adelantada a su tiempo histórico.

El Tratado y sus firmas. Washington, 18 de abril de 1890.

13. Martí, José. Madre América. Obras Completas. La Habana. 1975. Tomo VI. Pags. 133-140. Discurso pronunciado ante la sociedad literaria hispanoamericana.

14. Martí, José. Juan Carlos Gómez. La América, Nueva York, julio de 1884.

15. Martí, José. Simón Bolívar. Discurso pronunciado en la velada de la Sociedad Literaria Hispanoamericana en honor de Simón Bolívar el 28 de octubre de 1893. Patria, Nueva York, 4 de noviembre de 1893.

16. Martí, José. Heredia. El Economista Americano, Nueva York, julio de 1888.

17. Martí, José. A F. Henríquez Y Carvajal. Montecristi, 25 de marzo, 1895. 
A esto mismo hizo referencia Fidel Castro, al referirse a Martí: “de él recibimos igualmente su inspirador patriotismo y un concepto tan alto del honor y de la dignidad humana como nadie en el mundo podría habernos enseñado". ${ }^{18}$

Y más adelante en su discurso, Castro, continuará afirmando: “¿Por quién y por qué? Por los mismos que hoy luchan y los que mañana lucharán por los mismos sueños y esperanzas de salvar al mundo, y porque quiso el azar que hoy la humanidad perciba sobre ella y tome conciencia de los riesgos que él previó y advirtió con su visión profunda y su genial talento". ${ }^{19}$

Aunque la tarea sea local y particular, la visión y la misión son universales, como bien afirma Castro, al referirse a Martí, "la guerra de independencia de Cuba [...] es suceso de gran alcance humano, y servicio oportuno que el heroísmo juicioso de las Antillas presta a la firmeza y trato justo de las naciones americanas, y al equilibrio aún vacilante del mundo". ${ }^{20}$

Para Martí en la lucha por la independencia de Cuba respecto de España se juega el destino de la humanidad: "es un mundo lo que estamos equilibrando: no son dos islas las que vamos a libertar... un error en Cuba, es un error en América, es un error en la humanidad". ${ }^{21}$ Se trata de "la libertad humanitaria y expansiva, no local, ni de raza, ni de secta". ${ }^{22}$ No es cuestión de razas, sino de independencia o servidumbre de unos humanos respecto de otros.

Además, en Martí su visión de la unidad de la humanidad lo conduce a afirmar que "la América ha de promover todo lo que acerque a los pueblos, y de abominar todo lo que los aparte". ${ }^{23}$ La misión libertaria pasa por la unidad original y real de la humanidad. No tendría sentido para Martí tal misión si ésta no fuese encomendada por la misma naturaleza y humanidad.

La abundancia de bienes de la naturaleza es para todos los humanos, independientemente de sus diferencias étnicas, culturales y religiosas. Todos por el hecho de ser humanos han de poder disfrutar de una vida conforme a su humanidad. Se trata de la unidad de la humanidad en su diversidad. Los gobiernos tienen este mismo destino y misión, como indica Martí, "para llegar, con métodos e instituciones nacidas del país mismo, a aquel estado apetecible

18. Castro, Fidel. La gran batalla se librará en el campo de las ideas. Discurso pronunciado en la clausura de la Conferencia Internacional Por el Equilibrio del Mundo, en homenaje al aniversario 150 del natalicio de nuestro Héroe Nacional José Martí, en el Palacio de Convenciones, el 29 de enero del 2003.

19. Ibidem.

20. Ibidem.

21. Martí, José. Obras Completas. La Habana. Ed. Nac. de Cuba. 1975.

22. Marinelo Juan. Opcit.

23. Martí, José. Obras Completas. Editorial de Ciencias Sociales, La Habana, 1975. Texto citado por el embajador de Cuba, Pedro P. Prada Quintero, en el homenaje institucional de la Asamblea Legislativa de El Salvador a José Martí, con motivo del 160 aniversario de su natalicio, Plaza de las Banderas del Palacio Legislativo, San Salvador, 24 de junio de 2013. 
donde cada hombre se conoce y ejerce, y disfrutan todos de la abundancia que la Naturaleza puso para todos". ${ }^{24}$

Según afirma Pedro P. Prada Quintero, embajador de Cuba en El Salvador, "queríamos que se cumpliera el mandato martiano de que la ley primera de la República fuera el culto de los cubanos a la dignidad plena del hombre." 25 Al hablar de la dignidad plena del hombre se trata de la dignidad plena de cualquier humano, sea éste blanco o negro, hombre o mujer, empleado o empleador, cubano o norteamericano.

Si bien la libertad pasa por Cuba, esta libertad es el destino a disfrutar de toda la humanidad: "el mundo es un templo hermoso donde caben en paz los hombres todos de la tierra, porque todos han querido conocer la verdad, y han escrito en sus libros que es útil ser bueno, y han padecido y peleado por ser libres, libres en su tierra, libres en el pensamiento". ${ }^{26}$

Según Alberto Velásquez López y Ada Bertha Frómeta Fernández, “La máxima martiana en la interpretación entre justicia y política, es que el deber de la política es elevar hasta la justicia a la humanidad injusta, para así conducir hasta el bien común y propiciar intereses virtuosos". ${ }^{27}$ Y esta lucha políticomilitar por la independencia de Cuba se encamina a alcanzar la justicia para la humidad entera. En Cuba se niega la libertad que los mismos españoles reclaman para sí. Tal hecho es una contradicción tajante contra la unidad de la humanidad que defiende con su misma vida Martí. José Martí quiere para los cubanos la libertad y justicia que anhela para cualquier humano.

El mismo Martí en el Manifiesto de Montecristi declara un "radical respeto al decoro del hombre, nervio del combate y cimiento de la república". ${ }^{28}$ Para Martí se trata de abrir al mundo, incluida España, a la lucha de Cuba y a Cuba a la lucha por una humanidad libre y justa, como lo dice afirmando que "la revolución emplea sin miedo este lenguaje porque el decreto de emancipar de una vez a Cuba de la ineptitud y corrupción irremediables del gobierno de España, y abrirla franca para todos los hombres al mundo nuevo". ${ }^{29}$

Y añade Martí:

24. Ibidem. Texto citado por el embajador de Cuba, Pedro P. Prada Quintero, en el homenaje institucional de la Asamblea Legislativa de El Salvador a José Martí, con motivo del 160 aniversario de su natalicio, Plaza de las Banderas del Palacio Legislativo, San Salvador, 24 de junio de 2013.

25. Palabras del embajador de Cuba, Pedro P. Prada Quintero, en el homenaje institucional de la Asamblea Legislativa de El Salvador a José Martí, con motivo del 160 aniversario de su natalicio, Plaza de las Banderas del Palacio Legislativo, San Salvador, 24 de junio de 2013.

26. Martí, José. Opcit. Texto citado por el embajador de cuba, Pedro P. Prada Quintero. Ibid.

27. Velásquez L., Alberto y Ada Bertha Frómeta Fernández. Filosofía Política en José Martí. Pdf enviado por correo electrónico por la Dra. Magda Arias.

28. Martí, José. Manifiesto de Montecristi. Obras Completas. La Habana. 1975.

29. Ibidem. 
"La revolución cumplirá mañana el deber de explicar de nuevo al país y a las naciones las causas locales, y de idea e interés universal, con que para el adelanto y servicio de la humanidad reanuda el pueblo emancipador de Yara y de Guáimaro una guerra digna del respeto de sus enemigos y al apoyo de los pueblos, por su rígido concepto del derecho del hombre". ${ }^{30}$

Una gran claridad ilumina el pensamiento y la lucha de José Martí, que no debe pasar inadvertida y tampoco olvidada, sino, al contrario, advertir y recordar a lo largo de muchas nuevas generaciones: su concepto y su convicción sobre la unidad en la diversidad de la humanidad.

Esta unidad en la diversidad del humano no es vacía, sino que tiene un para qué: la lucha por y "en el rescate y sostén de la dignidad del hombre", a lo que Martí llamó “los deberes, y los intentos, de la revolución”. ${ }^{31}$

La vida y obra de Martí se dedicaron como él mismo señala a la lucha por "el bien mayor del hombre". ${ }^{32} \mathrm{Y}$ al referirse al "hombre", se refiere a cualquiera, o sea, a todos. Un humano cualquiera situado en sus circunstancias concretas, diverso en sus diferencias étnicas, culturales y económicas, pero perteneciente a una sola humanidad con un mismo destino.

\section{Conclusiones}

Para Martí no hay razas. No hay una especie superior y otras que sean inferiores por su color, su estatura, su educación, sus opciones políticas, su pobreza o riqueza económica. La humanidad es una en especie. Cualquier humano posee una dignidad que debe ser respetada, promovida y defendida.

Martí es defensor de la República, de una República libre y justa, donde cada humano pueda disfrutar de los bienes de la naturaleza y de la humanidad. Está en contra de un estado feudal que defiende la división humana entre siervos y señores, donde únicamente los señores tienen voz y voto en las decisiones que afectan la vida de otros o condenan a la miseria y a la muerte a los siervos.

Para Martí, la lucha, en las trincheras de las ideas y en los campos de batalla, es necesaria para alcanzar vencer al viejo mundo feudal y dar paso al nuevo mundo republicano y democrático. Y para alcanzar el triunfo se requiere de una visión y de una acción de unidad entre los humanos y las repúblicas americanas.

El viejo mundo feudal y el imperialismo amenazan con destruir las posibilidades de libertad y justicia que los latinoamericanos anhelan, luchan y esperan. $Y$ 
sólo una visión y acción de unidad en la diversidad pueden derrotarlos. El reto es grande, pero el desafío vale la pena.

\section{Referencias}

Castro, Fidel. La gran batalla se librará en el campo de las ideas. Discurso pronunciado en la clausura de la Conferencia Internacional Por el Equilibrio del Mundo, en homenaje al aniversario 150 del natalicio de nuestro Héroe Nacional José Martí, en el Palacio de Convenciones, el 29 de enero del 2003.

Marinelo, Juan. Fuentes y raíces del pensamiento de José Martí. Fundación Biblioteca de Ayacucho. Caracas. 2005.

Martí, José. Obras Completas. Ed. Nac. de Cuba. La Habana. 1975.

Prada Quintero, Pedro P. Palabras en el homenaje institucional de la Asamblea Legislativa de El Salvador a José Martí, con motivo del 160 aniversario de su natalicio, plaza de las banderas del Palacio Legislativo, San Salvador, 24 de junio de 2013.

Velásquez L., Alberto y Ada Bertha Frómeta Fernández. Filosofía Política en José Martí. Biblioteca de Ayacucho. Caracas. 2005. 